\title{
Plasma volume after heat acclimation: Variations due to season, fitness and methods of measurement
}

\author{
JA Loeppky \\ Department of Physiology, Lovelace Foundation for Medical Education and Research, \\ Albuquerque, NM, USA
}

Received: September 30, 2014

Accepted after revision: June 9, 2015

\begin{abstract}
Purpose: The reported magnitude of plasma volume increase ( $\Delta \% \mathrm{PV}$ ) following heat acclimation (HA) varies widely. Variations may result from differences in measurement techniques, season and subjects' fitness. This report compares direct and indirect measurements of $\Delta \% \mathrm{PV}$ after 10 days of HA from studies in winter (WIN, $n=8$ ) and summer (SUM, $n=10$ ) in men, age $21-43 \mathrm{yr}$, at two fitness levels $\left(\mathrm{VO}_{2} \max : 35\right.$ and $51 \mathrm{ml} / \mathrm{min} / \mathrm{kg}$ ). Direct measurements were made before and after $\mathrm{HA}$ (cycling at $30 \%$ of $\mathrm{VO}_{2} \max$ at $50{ }^{\circ} \mathrm{C}$, for $100 \mathrm{~min} /$ day) by carbon monoxide $(\mathrm{CO})$ rebreathing and compared with indirect estimates from changes in hematocrit, hemoglobin and plasma protein concentration. Results: Overall, $\Delta \% \mathrm{PV}$ by CO was small $(2.9 \%)$ and greater in SUM than WIN (5.0 vs. $0.3 \%$ ). Red cell, blood and plasma volumes $/ \mathrm{kg}$ lean body mass increased in SUM and decreased in WIN, the difference being significant, and $\Delta \% \mathrm{PV}$ by $\mathrm{CO}$ was similar for high and low $\mathrm{VO}_{2}$ max. Conclusion: Overall, indirect estimates of $\Delta \% \mathrm{PV}$ by hemoglobin and hematocrit were similar to $\mathrm{CO}$, but tended to differentiate by fitness and not season. The difference in THb increase in SUM and decrease in WIN was significant. This probably accounts for the differences from the seasonal and fitness results by the direct $\mathrm{CO}$ method.
\end{abstract}

Keywords: carbon monoxide rebreathing, hematocrit, heat acclimation, hemoglobin, human subjects, plasma proteins, seasonal effects

Heat acclimation (HA) is typically achieved by exercising daily in a hot environment over a period of a week or more (28). Successful HA increases the ability to work in the heat without excessive body temperature and heat illness symptoms. Common physiological correlates of this improved ability are attenuations in heart rate (HR), body temperature rise, electrolyte loss in sweat and increased sweating during subsequent dehydrating work. An increase in plasma volume (PV) is frequently measured and presumed to be advantageous to support the increased circulatory demands of working in the heat, along with plasma protein shifts that may attenuate intravascular fluid losses $(8,14,19,29)$.

The magnitude of the increase in PV with HA varies greatly in reports, ranging from zero (3) to $30 \%$ (31). Some variability undoubtedly results from differences in the subject's fitness, number of days, exercise intensity, temperature and hydration level in HA studies (10). Seasonal temperature variations wherein the artificial HA takes place may also affect the results (29). Reported HA studies have been predominantly performed on highly fit

Corresponding address: JA Loeppky

2725 7th Street South, Cranbrook, BC V1C 4R8, Canada

Phone: +250-489-4597; Fax: +250-426-4440; E-mail: Loeppkyj@telus.net 
individuals or workers in hot environments, with few studies comparing fitness levels during different ambient temperatures, i.e., winter and summer, which may superimpose additional variation (34).

Another source of non-uniform findings is the different methods employed to measure PV changes over the period of HA. Method comparisons are rare. Many studies have relied on indirect methods based on hemodilution of natural blood constituents such as erythrocyte $(\mathrm{Hct})$, hemoglobin $(\mathrm{Hb})$ and plasma protein $(\mathrm{PP})$ concentrations to estimate changes from a measured or assumed pre-HA baseline value. Pre- and post-HA indicator dilution measurements are advantageous because they are not affected by changes in the blood constituents or shrinkage or swelling of erythrocytes that affect indirect methods. One direct indicator method proven to be relatively sensitive and precise is the carbon monoxide $(\mathrm{CO})$ rebreathing method that measures total circulating hemoglobin (THb) $(4,11)$. Sawka et al. (30) noted that the CO method tends to give red cell volume (RCV) values some $15-20 \%$ higher than labelled isotope methods.

Two previous investigations used the CO method to evaluate the effects of HA on (a) the tolerance to dehydrating work in the heat (24) and (b) the tolerance to orthostatic stress before and after dehydrating exercise in the heat $(21,25)$. These two studies also included indirect measurement of PV changes from $\mathrm{Hct}$ and $\mathrm{Hb}$ and PP measurements before and after HA. Data from these studies were available to retrospectively determine possible contributors to the large diversity in the literature regarding the magnitude of PV and blood volume (BV) changes with HA.

In these studies the independent variable was HA and the dependent variables were a) exercise responses during dehydrating work in the heat and b) orthostatic tolerance. The resting baseline measurement of responses to HA reported here were made prior to these stressors being applied before and after HA.

The purpose of this presentation is to evaluate the effects of seasonal and fitness differences on PV changes from measurements obtained before and after successful HA by direct and indirect PV measurement techniques; the hypothesis was that no differences would be found between seasons, fitness level or methods of measurement.

\begin{tabular}{|c|c|c|c|}
\hline$\Delta \% \mathrm{PV}:$ & percentage change in plasma volume & PV: & plasma volume $(\mathrm{mL})$ \\
\hline BMI: & body mass index $\left(\mathrm{kg} / \mathrm{m}^{2}\right)$ & $\mathrm{R}:$ & recreational runners \\
\hline BV: & blood volume (mL) & RCV: & red cell (erythrocyte) volume (mL) \\
\hline BW: & body weight (kg) & RH: & relative humidity \\
\hline $\mathrm{CO}:$ & carbon monoxide & $\mathrm{S}_{\mathrm{CO}}$ : & percentage of carbon monoxide saturation of \\
\hline $\mathrm{COHb}:$ & carboxyhemoglobin & & hemoglobin \\
\hline HA: & heat acclimation & SUM: & study done in summer \\
\hline $\mathrm{Hb}:$ & hemoglobin concentration of whole blood $(\mathrm{g} / \mathrm{dL})$ & THb: & total circulating hemoglobin $(\mathrm{g})$ \\
\hline Hct: & percentage of erythrocytes in whole blood & TPP: & total plasma protein $(\mathrm{g})$ \\
\hline HR: & heart rate (beats/minute) & $\mathrm{T}_{\mathrm{RE}}:$ & rectal temperature \\
\hline LBM: & lean body (non-fat) mass $(\mathrm{kg})$ & $\mathrm{V}_{\mathrm{CO}}$ : & carbon monoxide uptake $(\mathrm{mL})$ \\
\hline NA: & unacclimated to heat & $\mathrm{VO}_{2} \max :$ & maximal $\mathrm{O}_{2}$ consumption during a ramp \\
\hline NR: & non-runners, sedentary life style & & ergometer test (ml/min/kg body wt) \\
\hline PP: & plasma protein concentration $(\mathrm{g} / \mathrm{dL})$ & WIN: & study done in winter \\
\hline
\end{tabular}




\section{Materials and Methods}

\section{Subjects}

The study protocols were approved by the Human Subjects Review Committee of The Lovelace Foundation. Each subject provided written informed consent. Eight healthy men were studied in the winter (WIN-January/February) and 10 in the summer (SUM-July/ August). Women were not included because the funding agency at that time required findings applicable to men. Outdoor temperature and relative humidity $(\mathrm{RH})$ in WIN and SUM averaged $10{ }^{\circ} \mathrm{C}-56 \% \mathrm{RH}$ and $32{ }^{\circ} \mathrm{C}-32 \% \mathrm{RH}$, respectively, at an altitude of $1,650 \mathrm{~m}$. The subjects were known to the investigators and volunteered. Subjects in both studies were partially selected based on their recreational habits, such that in each study half were classified as runners (R), who ran 20-35 miles/week (maintained throughout the studies), and half were more sedentary, denoted non-runners (NR). Two subjects, one NR and one R, took part in both studies. The aerobic capacity $\left(\mathrm{VO}_{2} \mathrm{max}\right)$ of each subject was first determined by a ramp bicycle ergometer test, as described by Luft et al. (23), and lean body mass (LBM) and percent fat by hydrostatic weighing (18).

Pertinent baseline measurements are given in Table I. Their age ranged from 21-43 yr. The average $\mathrm{VO}_{2}$ max values for NR were similar to that of a healthy sedentary population (20). No means were significantly different between the eight subjects in WIN and the 10 in SUM. However, when partitioned by fitness the nine Rs had lower fat content and body mass index (BMI) and tended to have a lower weight (BW), with significantly higher $\mathrm{VO}_{2} \mathrm{max}$ values, ranging from 44 to $55 \mathrm{vs} .27$ to $40 \mathrm{ml} / \mathrm{min} / \mathrm{kg}$ of BW for NRs.

Table I. Mean ( $\pm 1.0 \mathrm{SD})$ baseline measurements of 18 subjects partitioned by season and activity

\begin{tabular}{|l|c|c|c|c|c|c|c|c|}
\hline & $\mathbf{n}$ & Age & $\mathbf{H t}$ & $\mathbf{B W}$ & $\mathbf{B M I}$ & $\mathbf{L B M}$ & Fat & VO $_{2} \mathbf{m a x}$ \\
\cline { 3 - 9 } & & $\mathbf{( y r )}$ & $\mathbf{( c m )}$ & $\mathbf{( k g )}$ & $\mathbf{( k g / \mathbf { m } ^ { 2 } )}$ & $\mathbf{( k g})$ & $\mathbf{( \% )}$ & $\mathbf{( m l} / \mathbf{m i n} / \mathbf{k g})$ \\
\hline All & 18 & $32(7)$ & $176.6(7.7)$ & $75.2(14.4)$ & $24.1(4.0)$ & $62.9(8.7)$ & $15.5(8.0)$ & $42.8(9.1)$ \\
\hline Study A-WIN & 8 & $33(7)$ & $174.1(7.5)$ & $70.9(6.7)$ & $23.4(2.3)$ & $60.4(8.2)$ & $14.9(7.8)$ & $43.8(8.8)$ \\
\hline Study B-SUM & 10 & $31(7)$ & $178.6(7.1)$ & $78.7(18.1)$ & $24.6(5.0)$ & $65.0(8.9) \dagger$ & $16.0(8.6)$ & $42.0(9.7)$ \\
\hline Non-runners & 9 & $30(8)$ & $176.6(8.1)$ & $81.0(17.4)$ & $26.0(4.9)$ & $63.7(9.0)$ & $20.4(5.9)$ & $35.1(4.5)$ \\
\hline Runners & 9 & $34(5)$ & $176.6(7.7)$ & $69.4(7.9) \dagger$ & $22.2(0.9)^{*}$ & $62.1(8.8)$ & $10.6(6.8)^{*}$ & $50.6(4.5)^{*}$ \\
\hline
\end{tabular}

WIN: study done in winter; SUM: study done in summer.

Significance of difference from above group indicated by $*: P<0.05$ and $\uparrow: P<0.10$ (trend to significance)

\section{Heat acclimation}

In both studies HA and dehydrating ergometer exercise were performed at $50{ }^{\circ} \mathrm{C}$ dry bulb, $26{ }^{\circ} \mathrm{C}$ wet bulb $(\mathrm{RH} \approx 16 \%)$ at $30 \%$ of each subject's $\mathrm{VO}_{2}$ max in an environmental chamber with air movement at 3-4 m/s. In WIN, the first day baseline resting measurements were followed by an exercise without fluid replacement to exhaustion when subjects could no longer maintain the prescribed pedalling rate. This was followed by nine consecutive days of HA, with exercise continued for 100 minutes in the heat. Water and electrolyte deficits were replaced based on BW loss with flavored $0.1 \%$ saline during short rest intervals every 20 minutes. The men rested on day 11 and then on day 12 baseline measurements were made and 
exercise to exhaustion without water replacement was repeated as on day 1. In SUM, the same resting baseline measurements were followed by two orthostatic tolerance tests before and after exercise in the heat without fluid replacement. This was followed by an identical 9-day HA protocol of work in the heat as in WIN. After a rest day the baseline measurements were repeated, followed by the same two orthostatic and exercise tests. Thus, in both studies HA consisted of 10 days of work in the heat, the first day with no fluid replacement.

The effectiveness of HA was apparent in both studies. In WIN the exercise time without fluid replacement increased significantly from 77 to $112 \mathrm{~min}$ after HA, with the rise in HR and body temperature $\left(\mathrm{T}_{\mathrm{RE}}\right)$ being $43 \%$ and $39 \%$ lower, respectively $(P=0.001)$. The average evaporative rate increased $7 \%$ and the sweat electrolyte concentration decreased $18 \%$ after HA. In SUM, where these measurements during dehydrating exercise were not made, the success of HA was confirmed by reduced $\mathrm{HR}$ and $\mathrm{T}_{\mathrm{RE}}$ after the last (9th) HA exercise session compared to the first. The average rise in $\mathrm{HR}$ and $\mathrm{T}_{\mathrm{RE}}$ decreased by $38 \%$ and $32 \%$, respectively. The decrease in PV after dehydrating work in the heat before and after HA averaged $12 \%$ in both studies, with no significant difference between pre- and post-HA, or between WIN and SUM.

\section{Procedures and measurements of resting blood constituents before and after HA}

In both studies, before and after HA, the subjects were in a post-absorptive and euhydrated state. A flexible Teflon catheter was inserted into an antecubital vein and BW recorded within $\pm 15 \mathrm{~g}$. Following 45-60 min of rest in the recumbent position, baseline blood volume (BV) was obtained by measuring $\mathrm{THb}$ by the $\mathrm{CO}$ rebreathing method (26). An infrared method (27) was used to measure blood carboxyhemoglobin $(\mathrm{COHb})$ saturation $\left(\mathrm{S}_{\mathrm{CO}}\right)$ before and after rebreathing. Blood samples were also drawn for $\mathrm{Hb}$, Hct and PP without stasis from the indwelling catheter. Venous Hct was determined by the microhematocrit method, with no corrections for trapped plasma or difference between venous and whole body Hct. $\mathrm{The} \mathrm{Hb}$ concentration was determined by the Drabkin technique (7) using a Beckman DU spectrophotometer calibrated with HyceI methemoglobin standards. The PP concentration was determined by the Biuret method with an autoanalyzer (SMA-12, Technicon Corp) from venous samples taken during the CO rebreathing. Changes in PV, BV and RCV were also calculated from that day's baseline and post-HA baseline $\mathrm{Hb}$ and Hct according to equations summarized by Greenleaf et al. (13).

After $\mathrm{CO}$ rebreathing the $\mathrm{THb}$ was calculated as follows:

$\mathrm{THb}(\mathrm{g})=\left(\mathrm{V}_{\mathrm{CO}} \times 0.985 \times 100\right) /\left(1.34 \times \Delta \mathrm{S}_{\mathrm{CO}}\right)$

where: $\mathrm{V}_{\mathrm{CO}}=$ volume of $\mathrm{CO}$ in $\mathrm{ml}(\mathrm{STPD})$ introduced into the rebreathing circuit; $0.985=$ average fraction of $\mathrm{CO}$ taken up by the blood at the end of 10 min rebreathing; $1.34=\mathrm{CO}$ capacity of $1.0 \mathrm{~g}$ of $\mathrm{Hb}$ and $\Delta \mathrm{S}_{\mathrm{CO}}=$ the increase in $\mathrm{COHb}$ saturation after $\mathrm{CO}$ rebreathing. $\mathrm{BV}$ was then derived from $\mathrm{THb}$ and $\mathrm{Hb}$ concentration as:

$$
\mathrm{BV}(\mathrm{mL})=(\mathrm{THb} / \mathrm{Hb}) \times 100)
$$

and PV from BV and Het as:

$$
\mathrm{PV}(\mathrm{mL})=\mathrm{BV} \times(100-\mathrm{Hct}) / 100
$$

and RCV as:

$$
\mathrm{RCV}(\mathrm{mL})=\mathrm{BV}-\mathrm{PV}
$$


The percentage change in PV $(\Delta \% \mathrm{PV})$ after HA was calculated from $\mathrm{PV}$ values obtained by Eq. 3 and also calculated from PP measurements as:

$$
\Delta \% \mathrm{PV}=100 \times\left[\left(\mathrm{PP}_{\text {pre }} / \mathrm{PP}_{\text {post }}\right)-1\right]
$$

$\mathrm{The} \mathrm{Hb}$ content of red cells was estimated from the $\mathrm{Hb} / \mathrm{Hct}$ ratio. Total circulating protein (TPP) was obtained from PP - PV/100.

\section{Statistics}

Pre- (non-heat acclimated - NA) to post-HA differences were tested by paired-t-tests. Significant differences between WIN and SUM and R and NR were tested by one-way ANOVA. To test for interaction between activity level and season, a two-factor ANOVA without replication was performed on measurement differences before and after HA between $\mathrm{R}$ and NR and WIN and SUM. Significance of correlations between $\Delta \% \mathrm{PV}$ by the various methods was tested by standard linear least squares regression analyses. All $P$-values were considered significant at $P \leq 0.05$ and trends suggested by $P \leq 0.10$.

\section{Results}

\section{All subjects}

The baseline averages and mean changes $( \pm 1.0 \mathrm{SD})$ in measurements after HA are given in Table II and partitioned by season and fitness level. For all 18 subjects combined there was a small, but significant, increase in PV of $92 \mathrm{~mL}$ (2.9\%) after HA, measured by the CO method, contributing almost entirely to the significant increase in $\mathrm{BV}$, and reductions in $\mathrm{Hb}(P<0.05)$, Hct (n.s.) and a trend to increasing TPP. However, the large SD of 4.8 for $\Delta \% \mathrm{PV}$ indicated a wide variation in $\triangle \% \mathrm{PV}$, with a $95 \%$ confidence interval from -6.5 to $12.3 \%$.

\section{Season}

Baseline $\mathrm{Hb}$ and Hct were significantly lower in SUM than WIN by $1.2 \mathrm{~g} / \mathrm{dL}$ and $3.6 \%$, respectively, and PV tended to be larger. The $\Delta \% \mathrm{PV}$ and $\mathrm{BV}$ increased significantly in SUM after HA, with essentially no change in WIN, a significant seasonal difference. The $\mathrm{Hb}$ and Hct were lower after HA in both WIN and SUM, but not significantly. The $\mathrm{Hb} / \mathrm{Hct}$ ratio tended to decrease in WIN, indicating a swelling of erythrocytes with HA, but not significantly less than the small decrease in SUM. The TPP was significantly increased in SUM, mainly due to the $5 \%$ increase in $\triangle \% \mathrm{PV}$.

\section{Fitness}

Differences between R and NR were minor. The Rs had a larger PV at baseline than NRs. The NRs tended to increase PV (3.6\%) after HA, with reductions in $\mathrm{Hb}$ and Hct from hemodilution, and TPP tended to increase. The $2.2 \%$ increase in $\triangle \% \mathrm{PV}$ for Rs was not significant. In Rs the only significant change with $\mathrm{HA}$ was a reduction in $\mathrm{Hb} / \mathrm{Hct}$ ratio, attributable to their decrease in $\mathrm{Hb}$ and increase in RCV. The Hct did not change in Rs after HA, but decreased significantly in NR.

Because RCV, PV and BV correlate with LBM, values per LBM are shown in Fig. 1. The baseline values for RCV/LBM before HA were significantly lower during SUM than WIN. For all three measurements the values after HA decreased slightly in WIN and increased in SUM; these trend differences were all statistically significant. The same three measurements are shown in Fig. 2 for NR and R. The Rs had significantly higher baseline values for PV and BV than NR, but no changes with HA were significant. 


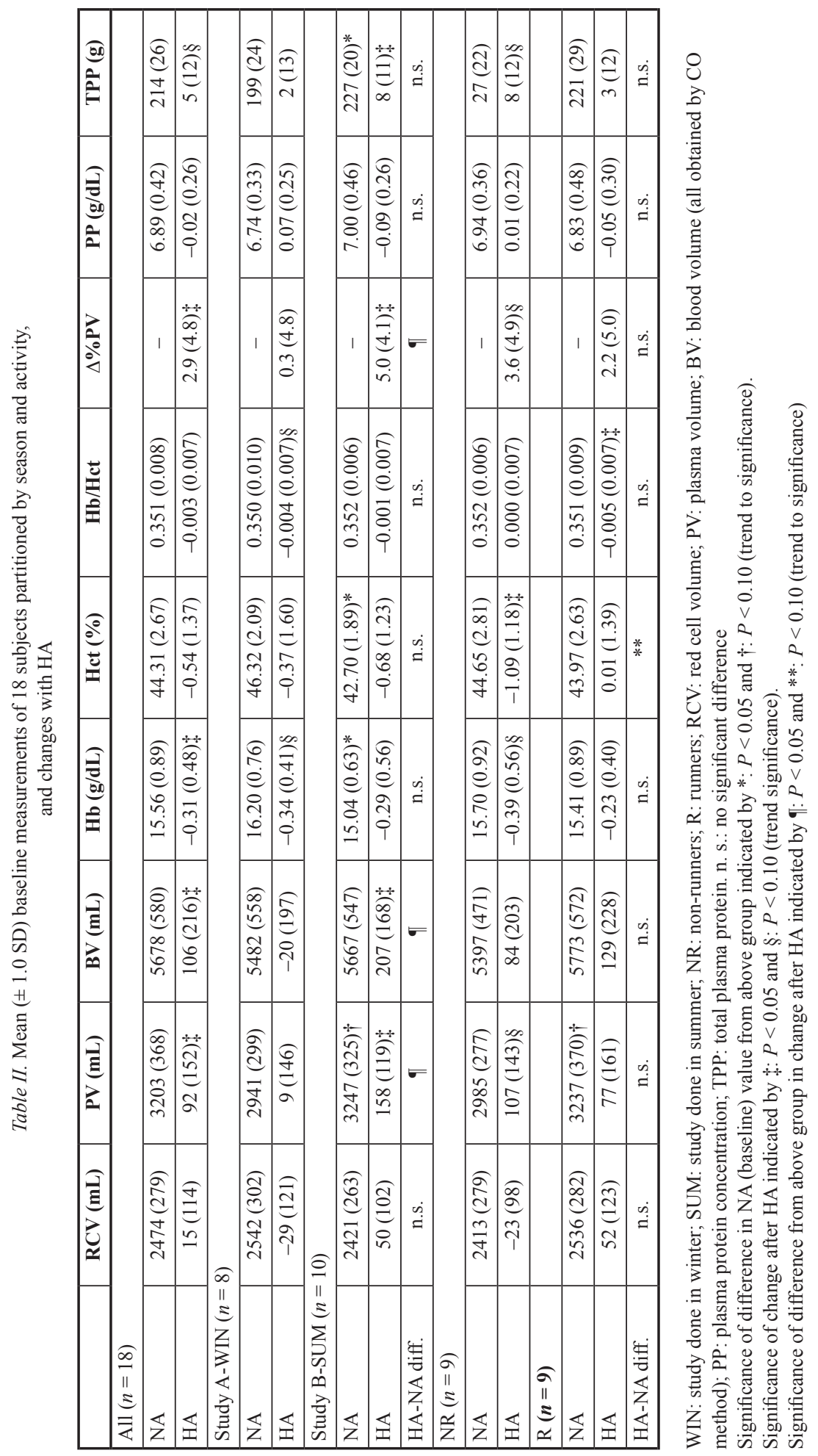




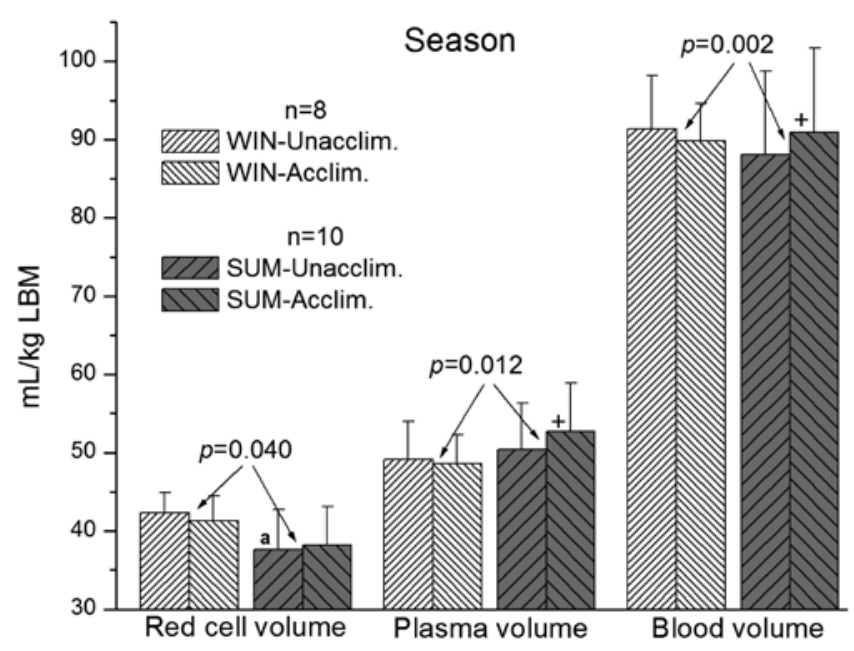

Fig. 1. Mean ( $\pm 1.0 \mathrm{SD})$ values of red cell, plasma and blood volume per kg of lean body mass (LBM) before and after heat acclimation for winter and summer studies. a: baseline value significantly $(P<0.05)$ lower in summer than winter; +: value significantly $(P<0.05)$ higher after heat acclimation than before. The $P$-levels are shown for significance of difference of changes with heat acclimation between seasons

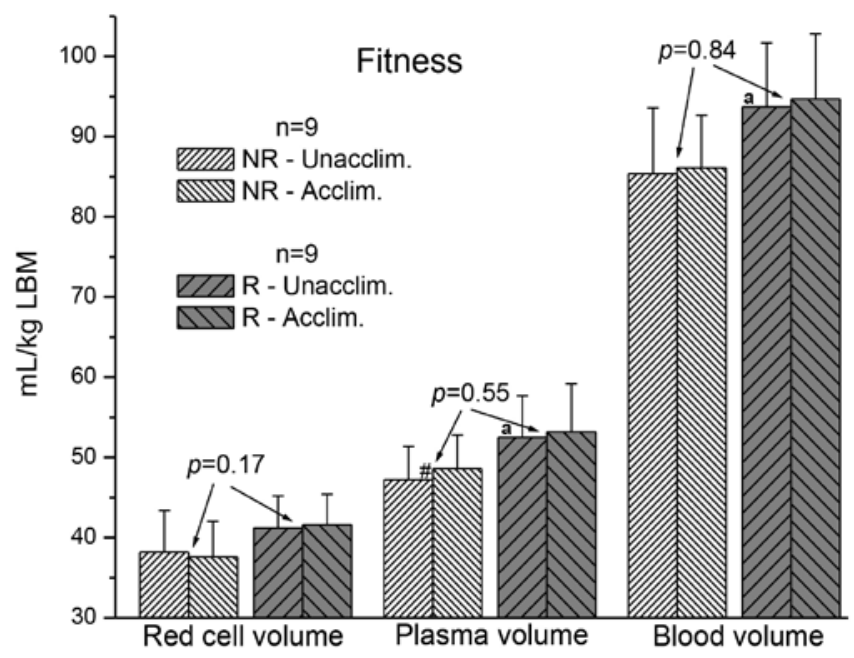

Fig. 2. Mean ( $\pm 1.0 \mathrm{SD})$ red cell, plasma and blood volume per kg of lean body mass (LBM) before and after heat acclimation for runners $(\mathrm{R})$ and non-runners $(\mathrm{NR})$ from both studies. a: baseline values significantly $(P<0.05)$ higher in R than NR; \#: value tends to be higher $(P<0.10)$ in NR after heat acclimation than before. The $P$-levels are shown (n.s.) for significance of differences of changes between $\mathrm{R}$ and NR with heat acclimation

Two-factor ANOVA analyses of all changes induced by HA shown in Table II and Figs. 1 and 2 did not indicate significant interaction between season and fitness level (all $P$-values for interaction $>0.20$ ). 


\section{Methods of measurement}

The $\Delta \% \mathrm{PV}$ values are presented in Table III for the four methods. For all 18 subjects $\Delta \% \mathrm{PV}$ was quite similar, as determined by the $\mathrm{CO}, \mathrm{Hb}+\mathrm{Hct}$ and Hct calculations (13). The $\Delta \% \mathrm{PV}$ based on PP shows trivial changes with HA in all groups. In WIN and SUM the two indirect $\mathrm{Hb}+\mathrm{Hct}$ and Hct estimates gave similar results for each season, in contrast to the $\mathrm{CO}$ values being significantly higher in SUM. Both indirect methods indicate a larger increase after HA for NR than $\mathrm{R}(\mathrm{Hb}+\mathrm{Hct}-\mathrm{n} . \mathrm{s}$. and Hct $-P<0.10)$, which is not apparent by the $\mathrm{CO}$ method. The correlations of $\mathrm{CO}$ measurements with those of $\mathrm{Hb}+\mathrm{Hct}$ and Hct are significant, but low, while the latter methods correlated closely with a slope near 1.0, indicating no overall change in erythrocyte volume $(\mathrm{Hb} / \mathrm{Hct}$ ratio) during $\mathrm{HA}$. Overall there was little change in $\mathrm{THb}$ with HA; however in WIN the loss of $23 \mathrm{~g}$ was significantly different $(P=0.038)$ than the $14 \mathrm{~g}$ gain during SUM. Opposite, but non-significant, changes in THb were noted for Rs and NRs. The overall changes in $\mathrm{THb}$ were closely associated with the $\mathrm{CO}$ minus $\mathrm{Hb}+\mathrm{Hct}$ method differences in $\Delta \% \mathrm{PV}(n=18, r=0.99)$; they were also closely associated with the CO minus Hct method differences $(r=0.90)$, while the correlation of $\mathrm{THb}$ changes with the $\mathrm{Hb}+\mathrm{Hct}$ minus Hct methods was low $(r=0.15)$.

Table III. Mean $( \pm 1.0 \mathrm{SD})$ changes in $\Delta \% \mathrm{PV}$ and THb with HA and correlations $(n=18)$ between methods

\begin{tabular}{|c|c|c|c|c|c|c|c|c|c|}
\hline \multicolumn{8}{|c|}{ Methods } & \multicolumn{2}{|c|}{ Correlations } \\
\hline & & & & & & & & $r$ & $P$ \\
\hline Group & $\mathrm{n}$ & $\mathrm{CO}$ & Hb+Hct & Het & PP & THb (g) & CO vs. Hb+Hct & 0.64 & 0.004 \\
\hline All & 18 & $2.9(4.8)+$ & $3.2(5.6) \%$ & $2.4(5.7) \S$ & $0.3(3.7)$ & $-2(38)$ & CO vs. Hct & 0.63 & 0.005 \\
\hline WIN & 8 & $\begin{array}{c}0.3(4.8) \\
\end{array}$ & $\begin{array}{c}3.0(5.6) \\
\text { n.s. }\end{array}$ & $\begin{array}{c}1.7(6.7) \\
\text { n.s. }\end{array}$ & $\begin{array}{c}-0.9(3.6) \\
\text { n.s. }\end{array}$ & $\begin{array}{c}-23(36) \S \\
\text { व }\end{array}$ & CO vs. PP & 0.17 & 0.51 \\
\hline SUM & 10 & $5.0(4.1) \ddagger$ & $3.3(5.9)$ & $2.9(5.1)$ & $1.3(3.6)$ & $14(33)$ & $\mathrm{Hb}+\mathrm{Hct}$ vs. Hct & 0.94 & $<0.001$ \\
\hline NR & 9 & $\begin{array}{c}3.6(4.9) \S \\
\text { n.s. }\end{array}$ & $\begin{array}{c}4.7(6.0) \ddagger \\
\text { n.s. }\end{array}$ & $\begin{array}{c}4.6(5.1) \neq \\
* *\end{array}$ & $\begin{array}{c}-0.1(3.2) \\
\text { n.s. }\end{array}$ & $\begin{array}{c}-9(34) \\
\text { n.s. }\end{array}$ & $\mathrm{Hb}+$ Hct vs. PP & 0.39 & 0.11 \\
\hline $\mathrm{R}$ & 9 & $2.2(5.0)$ & $1.6(5.0)$ & $0.1(5.6)$ & $0.7(4.2)$ & $4(43)$ & Het vs. PP & 0.28 & 0.26 \\
\hline
\end{tabular}

$\Delta \% \mathrm{PV}$ : percentage change in plasma volume

WIN: study done in winter; SUM: study done in summer

NR: non-runners; R: runners

$\mathrm{CO}$ : carbon monoxide rebreathing

$\mathrm{Hb}+\mathrm{Hct}$ : calculated from $\mathrm{Hb}$ and $\mathrm{Hct}$, assuming no change in total circulating $\mathrm{Hb}$ or red cell volume

Hct: calculated from Hct, assuming no change in total circulating $\mathrm{Hb}$

PP: calculated from PP concentration, assuming no change in total circulating PP

n.s.: no significant difference

$\mathrm{THb}$ : total circulating $\mathrm{Hb}$

Significance of change after HA indicated by $\ddagger: P<0.05$ and $\S: P<0.10$ (trend to significance)

Significant difference between groups in change after HA indicated by $\Phi: P<0.05$ and $* *: P<0.10$ (trend to

significance)

\section{Additional observations}

As mentioned previously, the decrease in PV after dehydrating work in the heat before and after HA averaged $12 \%$ in both studies, with no significant difference between pre- and postHA, or between WIN and SUM or R and NR. The correlation between $\Delta \% \mathrm{PV}$ measured by the $\mathrm{CO}$ method and the difference in PV lost during dehydrating work in the heat before and after HA for all subjects $(n=18)$ was low $(r=0.09)$. 


\section{Discussion}

Direct measurements by $\mathrm{CO}$ rebreathing demonstrated a small increase in $\Delta \% \mathrm{PV}$ (Table II) over 10 days of HA in all 18 subjects, with a significant increase in BV and insignificant increase in RCV. These changes occurred almost entirely in SUM. The changes in these measurements were essentially independent of the fitness level. The small changes in $\Delta \% \mathrm{PV}$, even in SUM, bring into question the significance of a PV increase during HA. It did not prevent or change the decrease in PV during the dehydrating work in the heat after HA. The physiological benefits of the PV increases during HA are also questionable based on the low correlation observed between $\Delta \% \mathrm{PV}$ during $\mathrm{HA}$ and the differences in $\mathrm{PV}$ lost during dehydrating work in the heat before and after HA for all subjects.

The TPP values tended to be larger after HA, mainly in SUM and in NR. This increase has been considered to be an important result of HA, by affecting plasma oncotic pressure to maintain intravascular volume and thereby delay circulatory failure with dehydration (14). The lack of $\Delta \% \mathrm{PV}$ noted by the PP estimation and its lack of relationship to the other three methods (Table III) suggests that protein flux in or out of the vascular space during HA invalidates estimates of PV changes by PP under these conditions.

Lower baseline $\mathrm{Hb}$ and Hct levels before HA in SUM (Table II) may be related to the seasonal difference in $\Delta \% \mathrm{PV}$. A number of reports have noted similar seasonal differences in samples from the general population $(15,16,17,31,33)$. Part of the reduction of $\mathrm{Hb}$ and $\mathrm{Hct}$ in the warmer summer is likely attributable to natural HA occurring because of higher ambient temperatures increasing PV for sweating or evaporative heat loss demand. Recreational training before and after HA by Rs in this study, superimposed on the artificial HA, may have attenuated their PV increase by contributing to their higher baseline BV and PV before HA. The contribution of training in warmer ambient temperatures superimposed on artificial HA has been pointed out by Shapiro et al. (34), who found that PV expanded more in the summer, as shown here (Table II). Other reports have also pointed out the influence of training on $\mathrm{Hb}$ and Hct (2).

Higher fitness levels are an important asset in performing in the heat and improving the effectiveness of HA $(1,5,6)$. Conversely, HA seems effective in improving endurance performance in temperate environments $(9,22)$. However this report found no significant difference in PV changes after HA related to fitness; nor was the exercise time in dehydrating heat increased more for Rs than NRs.

Differences in experimental protocols and measurement techniques also contribute to variability of reported PV changes with HA. Baseline PV is often measured by indicator dilution methods like Evans blue or isotopes to label plasma albumin, or CO rebreathing or isotopes to label erythrocytes and measure RCV. Short term changes due to exercise, dehydration, etc. are then commonly estimated by changes in $\mathrm{Hb}+\mathrm{Hct}$ or only Hct, to obtain $\triangle \% \mathrm{PV}$. These two should give similar results if $\mathrm{THb}$ is unchanged and there is no change in erythrocyte volume resulting from changes in plasma osmolality (13). However, the values in Table III indicate that the difference between the THb decreases with HA in WIN and the increase in SUM was significant. The close association of changes in $\mathrm{THb}$ with the $\mathrm{CO}$ minus $\mathrm{Hb}+\mathrm{Hct}$ method differences in $\Delta \% \mathrm{PV}$ and the close association with the $\mathrm{CO}$ minus Hct method differences indicate that the assumption of no change in $\mathrm{THb}$ from baseline after 10 days of HA was not valid, making these indirect estimations suspect for measuring $\Delta \% \mathrm{PV}$ after HA. The low correlation of THb changes with the $\mathrm{Hb}+\mathrm{Hct}$ vs. Hct method differences was low, probably indicating random measurement error of $\mathrm{Hb}$ and $\mathrm{Hct}$. $\mathrm{THb}$ may be expected to decrease with HA exercise in NRs because of increased erythrocyte turnover resulting 
from daily exercise to which they were not accustomed (32). The reduction in THb in WIN and increase in summer is more difficult to explain; differences in diet and nutrition may be involved (35), or perhaps the HA exercises in WIN were more stressful than in SUM when superimposed on a background of relative inactivity for both R and NRs (12).

\section{Conclusions}

This report indicates that the mean PV increase after 10 days of HA is small but can vary widely when measured directly with the $\mathrm{CO}$ method, and of questionable benefit for subsequent dehydrating work. The PV increase by the CO method is larger in summer than winter and independent of aerobic capacity. Indirect methods based on $\mathrm{Hb}$ and Hct give generally similar results, but may not differentiate between seasons and tend to introduce questionable differences based on aerobic capacity because of changes in THb during HA.

\section{Acknowledgements}

These two studies were supported by the NASA grants, NAS 9-12572 and NAS 9-14472. They were performed in the laboratories of the Department of Physiology, Lovelace Foundation for Medical Education and Research, Albuquerque, NM, USA. The experiments were carried out by Loren G Myhre, Ph.D. (1936-2012), under the supervision of Dr. U. C. Luft (1910-1991), with the technical support of the author, Mr J. Hopkins and Mrs. A. Elliott. The author appreciates the statistical assistance by Dr. E. R Fletcher. The dedicated help and friendly cooperation of the subjects taking part in these studies is greatly appreciated.

\section{REFERENCES}

1. Armstrong LE, Maresh CM: The induction and decay of heat acclimatisation in trained athletes. Sports Med. 12 , 302-312 (1991)

2. Banfi G, Lundby C, Robach P, Lippi G: Seasonal variations of haematological parameters in athletes. Eur. J. Appl. Physiol. 111, 9-16 (2011)

3. Bass DE, Buskirk ER, Iampietro PF, Mager M: Comparison of blood volume during physical conditioning, heat acclimatization and sedentary living. J. Appl. Physiol. 12, 186-188 (1958)

4. Burge CM, Skinner SL: Determination of hemoglobin mass and blood volume with CO: evaluation and application of a method. J. Appl. Physiol. 79, 623-631 (1995)

5. Cadarette BS, Sawka MN, Toner MM, Pandolf KB: Aerobic fitness and the hypohydration response to exerciseheat stress. Aviat. Space Environ. Med. 55, 507-512 (1984)

6. Cheung SS, McLellan TM: Heat acclimation, aerobic fitness, and hydration effects on tolerance during uncompensable heat stress. J. Appl. Physiol. 84, 1731-1739 (1998)

7. Drabkin DL: The standardization of hemoglobin measurement. Am. J. Med. Sci. 215, 110-111 and 217, 710$711(1948-1949)$

8. Fortney SM, Senay LC, Jr: Effect of training and heat acclimation on exercise responses of sedentary females. J. Appl. Physiol. Respir. Environ. Exerc. Physiol. 47, 978-984 (1979)

9. Garrett AT, Creasy R, Rehrer NJ, Patterson MJ, Cotter JD: Effectiveness of short-term heat acclimation for highly trained athletes. Eur. J. Appl. Physiol. 112, 1827-1837 (2012)

10. Garrett AT, Goosens NG, Rehrer NJ, Patterson MJ, Harrison J, Sammut I, Cotter JD: Short-term heat acclimation is effective and may be enhanced rather than impaired by dehydration. Am. J. Hum. Biol. 26, 311-320 (2014)

11. Gore CJ, Hopkins WG, Burge CM: Errors of measurement for blood volume parameters: a meta-analysis. J. Appl. Physiol. 99, 1745-1758 (2005)

12. Green HJ, Thomson JA, Ball ME, Hughson RL, Houston ME, Sharratt MT: Alterations in blood volume following short-term supramaximal exercise. J. Appl. Physiol. Environ. Exerc. Physiol. 56, 145-149 (1984) 
13. Greenleaf JE, Convertino VA, Mangseth GR: Plasma volume during stress in man: osmolality and red cell volume. J. Appl. Physiol. Respir. Environ. Exerc. Physiol. 47, 1031-1038 (1979)

14. Harrison MH, Edwards RJ, Graveney MJ, Cochrane LA, Davies JA: Blood volume and plasma protein responses to heat acclimatization in humans. J. Appl. Physiol. Respir. Environ. Exerc. Physiol. 50, 597-604 (1981)

15. Hightower CM, Hightower JD, Vázquez BY, Intaglietta M: Seasonal hematocrit variation and health risks in the adult population of Kinshasa, Democratic Republic of Congo. Vasc. Health Risk Manag. 5, 1001-1005 (2009)

16. Hoekstra T, Veldhuizen I, van Noord PA, de Kort WL: Seasonal influences on hemoglobin levels and deferral rates in whole-blood and plasma donors. Transfusion 47, 895-900 (2007)

17. Kristal-Boneh E, Froom P, Harari G, Shapiro Y, Green MS: Seasonal changes in red blood cell parameters. Br. J. Haematol. 85, 603-660 (1993)

18. Lim TP, Luft UC: Body density, fat, and fat-free weight. Am. J. Med. 30, 825-832 (1961)

19. Lindinger MI, McCutcheon LJ, Ecker GL, Geor RJ: Heat acclimation improves regulation of plasma volume and plasma $\mathrm{Na}(+)$ content during exercise in horses. J. Appl. Physiol. 88, 1006-1013 (2000)

20. Loeppky JA, Luft UC: Work capacity, exercise responses and body composition of professional pilots in relation to age. Aviat. Space Environ. Med. 60, 1077-1084 (1989)

21. Loeppky JA, Myhre LG, Venters MD, Icenogle MV, Kobayashi Y: Effects of running training and hypovolemia on LBNP tolerance. Advances in Exercise and Sports Physiology 11, 69-76 (2005)

22. Lorenzo S, Halliwill JR, Sawka MN, Minson C: Heat acclimation improves exercise performance. J. Appl. Physiol. 109, 1140-1147 (2010)

23. Luft UC, Cardus D, Lim TP, Anderson EC, Howarth J: Physical performance in relation to body size and composition. Ann. NY Acad. Sci. 110, 795-808 (1963)

24. Luft UC (1973): Body fluids and electrolytes under conditions of single and combined stress. In: Report on Specialized Physiological Studies in Support of Manned Space Flight, contract NAS 9-12572 February; NASA, LBJ Space Center, Biomedical Research Division, Houston, TX. pp. C1-C18

25. Luft UC (1976): A study of factors affecting tolerance to gravitational stress simulated by lower body negative pressure. In: Report on Specialized Physiological Studies in Support of Manned Space Flight, contract NAS 9-14472 February; NASA, LBJ Space Center, Biomedical Research Division, Houston, TX. pp. I1-I27

26. Myhre LG, Brown DK, Hall FG, Dill DB: The use of carbon monoxide and T-1824 for determining blood volume. Clin. Chem. 14, 1197-1205 (1968)

27. Myhre LG: Comparison of manometric and infrared methods for determining carbon monoxide in blood. Clin. Chem. 18, 909-910 (1972)

28. Pandolf KB: Time course of heat acclimation and its decay. Int. J. Sports Med. 19(Suppl 2), S157-S160 (1998)

29. Patterson MJ, Stocks JM, Taylor NA: Sustained and generalized extracellular fluid expansion following heat acclimation. J. Physiol. 559(Pt 1), 327-334 (2004)

30. Sawka MN, Convertino VA, Eichner ER, Schnieder SM, Young A: Blood volume: importance and adaptations to exercise training, environmental stresses, and trauma/sickness. Med. Sci. Sports Exerc. 32, 332-334 (2000)

31. Sawka, MN, Coyle EF (1999): Influence of body water and blood volume on thermoregulation and exercise performance in the heat. In Exercise and Sport Sciences Reviews, ed Hollozsy JO, Williams \& Wilkins, Baltimore, MD, pp. 167-218

32. Schmidt W, Maassen N, Trost F, Böning D: Training effects on blood volume, erythrocyte turnover and haemoglobin oxygen binding properties. Eur. J. Physiol. Occup. Physiol. 57, 490-498 (1988)

33. Sebok MA, Notari EP, Chambers LA, Benjamin RJ, Eder AF: Seasonal temperature variation and the rate of donor deferral for low hematocrit in the American Red Cross. Transfusion 47, 890-894 (2007)

34. Shapiro Y, Hubbard RW, Kimbrough CM, Pandolf KB: Physiological and hematologic responses to summer and winter dry-heat acclimation. J. Appl. Physiol. Respir. Environ. Exerc. Physiol. 50, 792-798 (1981)

35. Shiraki K, Yamada T, Yoshimura H: Relation of protein nutrition to the reduction of red blood cells induced by physical training. Jpn. J. Physiol. 27, 413-421 (1977) 